\title{
Evaluation of the stability of industrialized food emulsions, using rheology and digital image processing
}

\begin{abstract}
The development of industrialized dressings is an arduous task, it is necessary to ensure their stability and their sensory and rheological properties. For this, knowledge and experience are necessary in identifying the ingredients and processes that will ensure a quality product for the consumer. In the present work, viscosity and stability were analyzed by digital image processing of six salad dressings being them: three different brands with lemon flavor; three of the same brands with different flavors (Homemade, Italian and Rose); and lemon flavored dressing prepared in the laboratory. The image processing analysis showed that the process of stability loss in commercial lemon sauces tends to occur by molecular diffusion because it presented a linear growth curve over the time of storage. The samples of Rose and Italian sauce had minimal loss of stability, not allowing to distinguish the mechanism of destabilization. However, the homemade dressing presented a flocculation process, whereas in the lemon dressing prepared in the laboratory was not identified the mechanism of loss of stability. Regarding the rheological characteristics, all sauces studied presented pseudoplastic behavior and it was possible to observe an increase in viscosity of the dressings containing modified starch.
\end{abstract}

Keywords: emulsion, stability, image, viscosity, biopolymers
Volume I Issue 2 - 2015

\author{
Lívia Santana, Bianca Morcillo, Kelly A Silva, \\ Maria Alice Z Coelho
}

Biochemical Engineering Department, Federal University of Rio de Janeiro, Brazil

\author{
Correspondence: Maria Alice Z Coelho, Biochemical \\ Engineering Department, Federal University of Rio de Janeiro, \\ Edificio do Centro de Tecnologia, BI. E, lab. I03, Brazil, \\ Email alice@eq.ufrj.br
}

Received: April 29, 20I5 | Published: June 25, 2015

\section{reroduction}

\section{Introduction}

Emulsions are defined as thermodynamically unstable systems and, for being constituted by two immiscible phases, it is necessary to add emulsifiers or surfactants to ensure its stability for a reasonable period of time. Emulsified products are widely used in the food industry, in which we can point out the salad dressings. The consumption of salad dressings increases daily and new brands are investing in this business. For the entry of women into the job market and the search for an ideal body, the use of fast and easy to prepare meals is exploited by the industry, suggesting, therefore, salads as healthy dishes and dressings along with them. However, very little information is available regarding the physical and chemical characterizations of this type of product, which is possibly due to the instability of the salad dressings, thus making it necessary to further study this area. Digital image processing is a tool that can be used as a method for counting and measuring micelle sizes of the emulsions because this method allows to automatically extract and to identify information and to improve the visual quality of certain structural aspects. ${ }^{1}$ Moreover, this is a growing area; it addresses several multidisciplinary scientific topics. This process involves steps such as: acquisition and image processing, enhancement, segmenting information, parameterization, recognition and quantitative analysis. ${ }^{2}$ The rheological properties are related to the texture of the food, the viscosity being a feature used in quality control of salad dressings. ${ }^{3}$ The rheological behavior of the emulsions consists in testing measures of the shear stress, generating flow curves. The assays can be performed with the use of rotational or tube viscometers. ${ }^{4}$ The main physical-chemical and organoleptic characteristics of food emulsions depend on the size of the droplets; including stability, texture, appearance and flavor. It is therefore important to observe the main factors that determine the size of the oil droplets during homogenization. ${ }^{5}$ Therefore, to improve the quality of the oil and increase the shelf life, it is important to be able to predict and try to control any possible mechanism of destabilization. This study aimed to characterize the rheological behavior and to identify which type of physical destabilization process that occurs over time in commercial salad dressings using rheological parameters as tools and digital image processing.

\section{Materials and methods}

\section{Selection of the dressings and preparation of the samples}

Four brands of commercial salad dressings sold in a local supermarket in the city of Rio de Janeiro were chosen. Among the brands of three different dressings were lemon-flavored brands (brand $\mathrm{A}, \mathrm{B}$ and $\mathrm{C}$ ) and only the sample $\mathrm{C}$ had lemon juice in the composition. The other three salad dressings were the same brand (brand D), but the Italian type; Homemade type and Rose type. Furthermore, a dressing was made, containing extra virgin olive oil and lemon juice in a $50 \% \mathrm{v} / \mathrm{v}$ for comparison purposes; since it was the emulsion which presented best stability results. ${ }^{6}$ The homogenization of this sample was performed using Ultra Turrax T25 Basic from IKA ${ }^{\circledR}$. All samples were placed in $50 \mathrm{ml}$ falcon tube with a cap, and kept still stored at $4^{\circ} \mathrm{C}$. In Table 1 you can see which polymers described on the product label and which were specified as a thickener/stabilizer.

\section{Rheology}

The rheological parameters were determined with the rotational 
rheometer ARES-TA ${ }^{\circledR}$ (Advanced Rheometric Expansion System). In this device thermostatic bath was attached and the Orchestrator TM software was used. ${ }^{6}$ The study was performed at $25^{\circ} \mathrm{C}$ and at a frequency of $0.2 \mathrm{~Hz}$ with the geometry of a concentric cylinder (Couette). The sensors had the following dimensions: diameter of the cup $=34 \mathrm{~mm}$; concentric cylinder diameter $=32 \mathrm{~mm}$ and length $=33 \mathrm{~mm}$ cylinder. In the flow intensity test, the shear rate had a logarithmic increase of $0.10 \mathrm{~s}^{-1}$ to $450 \mathrm{~s}^{-1}$. The determination of shear rate (y), shear stress $(\sigma)$ and coefficient of viscosity $(\eta)$ were evaluated after 20 days of opening bottles of the commercial samples and of sample preparation. The power law model described by equation 1 was applied to the obtained curves using Excel. By this law, we have that when $n>1$ the fluid is classified as dilatant, if $n=1$ is classified as Newtonian and when $\mathrm{n}<1$, as a pseudoplastic fluid.

$$
\sigma=K^{*} \gamma n
$$

Table I Biopolymer listed on the product label of each dressing analyzed

\begin{tabular}{ll}
\hline Brand/Type & Polymers \\
\hline A / Lemon & Modified Starch/Xanthan gum** \\
B / Lemon & Xanthan gum* \\
C / Lemon & Maltodextrin/Xanthan gum* \\
D /Homemade & $\begin{array}{l}\text { Modified Starch/Crystal Celulose } \\
\text { cristalin*/Xanthan gum* }\end{array}$ \\
D / Rose & $\begin{array}{l}\text { Modified Starch/Polisorbate 60**/Xanthan } \\
\text { gum** }\end{array}$ \\
D / Italian & $\begin{array}{l}\text { Xanthan gum* } \\
\end{array}$
\end{tabular}

*Thickener $/ * *$ Stabilizer

\section{Digital image processing}

All samples were diluted so that they could be better displayed on the microscope. The four lemon flavored emulsions and the Italian type dressing were diluted, $50 \mu \mathrm{L}$ of the sample for $250 \mu \mathrm{L}$ of distilled water in a $2 \mu \mathrm{l}$ eppendorf. A sample of $25 \mu \mathrm{L}$ of the homemade salad dressing was diluted in $1000 \mu \mathrm{L}$ of distilled water and a sample of $25 \mu \mathrm{L}$ of the Rose type sauce was diluted in $1100 \mu \mathrm{L}$ of distilled water. Of these dilutions, $20 \mu \mathrm{L}$ were placed on a glass slide and overlaid with a coverslip in order to observe the micelles in the optical microscope. An optical microscope (Eclipse E200, Nikon ${ }^{\circledR}$ ) coupled to a digital camera (Evolution VF colled color fast, Media Cybernetics ${ }^{\circledR}$ ) linked to a personal computer was used to acquire images of the dressings. The magnification used was $40 \mathrm{x}$, as for the Rose dressing the magnification used was of $100 \mathrm{X}$. The images obtained were processed with a program developed in Matlab v.7.0.4. ${ }^{6,7}$ A micrometer and the Image-Pro plus 5.0 software were used to calibrate and enable the correlation of pixel measurement of micrometer of the images and to obtain the size of the micelles. Images were obtained every 7 days during 84 days of storage in a refrigerator $\left(4^{\circ} \mathrm{C}\right)$. On average 500 micelles were obtained for each day of the experiment.

\section{Destabilization}

The physical degradation of the emulsion is due to a spontaneous tendency to reduce the Gibbs free energy, which is achieved by reducing the size of the oil/water interface and the interfacial tension between the continuous and dispersed phases. The reduction of interfacial area is derived mainly from two mechanisms: the coagulation followed by the coalescence; and molecular diffusion. According to the theory of van den Tempel, degradation by coalescing the emulsion is characterized by a broadening of the size distribution of droplets with an exponential increase in the average droplet size over time was used..$^{5-7}$ Although, the Lifshitz-Slyozov-Wagner theory says that the mechanism of molecular diffusion is characterized by a linear increase of the emulsion's droplets' sizes over time. As the thickening of the emulsions by molecular diffusion is due to the gradual growth of larger emulsion droplets at the expense of smaller ones. This is a direct consequence of the Kelvin effect, which states that the solubility of a particle inversely proportional to its radius; meaning that the individual molecules tend to leave smaller particles and diffuse through the continuous phase to join the larger ones. ${ }^{5-7}$ The digital image processing is the tool used to detect by which mechanism the emulsions tend to destabilize over time.

\section{Results and discussion}

\section{Analysis of the rheological behavior}

According to the data obtained, it was possible to observe that the shear stress of all the analyzed dressings increased with the shear rate (Figure 1). Studies affirm that fluids in which the shear rate is not directly proportional to deformation rate are called Non-Newtonian fluids. ${ }^{8}$ According to Braun and Rosen, ${ }^{9}$ the pseudoplastic behavior is characterized by the fact that the decrease in viscosity with the increase in the shear rate, which can be applied to all dressings in this study (Figure 2). This can be explained due to hydrodynamic forces which become more intense, causing a progressive rupture and an elongation of the system which allows an alignment with the flow and, consequently, a reduction in the viscosity. ${ }^{3}$ The pseudoplastic behavior of dressings studied was also proven by applying the power law that generated, for all the dressings studied, a level of rheological behavior (n) lower than 1, with a coefficient of determination $\left(\mathrm{R}^{2}\right)$ greater than 0.98 for result adjustment from the power law, similar to that found by other author for the soymilk-based creamy dressing. ${ }^{10}$ The unexpected behavior of the shear stress presented by the Italian dressing, with the increase of shear rate, made it impossible to calculate the power law parameters. This unusual behavior can be related to experimental errors associated to the methodology used. However, the behavior of the coefficient of viscosity with the increase of the shear rate confirms the previous finding in which all the dressings studied can be classified as pseudoplastic. According to Brazilian laws, the food industry does not need to state on the product label the amount of additives used as emulsifiers and stabilizers; it just has to name the additive and its purpose in the product. However, according to the rheological behavior, it was observed that the Homemade and the Rose dressings of the D brand had the highest viscosity presented similar results. The homemade type presented in its composition microcrystalline cellulose and xanthan gum as a thickener and propylene glycol alginate as stabilizer, in addition to the modified starch. The sauce kind Rose also had modified starch, specified only as a stabilizer besides polysorbate 60 and xanthan gum. All the aforementioned polysaccharides are often used in food emulsions in order to thicken and stabilize. As for the modified starch, depending on the modification made, it is able to reduce the viscosity or swell the starch pellets without it rupturing, which provides viscosity for a longer period of time, thereby increasing the stability of emulsions. ${ }^{11}$ Although the xanthan gum's 
viscosity is barely affected by the variation of $\mathrm{pH}$ (1 to 11) or by temperatures up to $100^{\circ} \mathrm{C}$, while the alginate increases the viscosity at a $\mathrm{pH}$ lower than 4 and in the presence of calcium ions. ${ }^{12}$ It is known that the microcrystalline cellulose tends to increase viscosity when the temperature is between 20 and $60^{\circ} \mathrm{C}$. Nishinari suggested that there is formation of a dispersing fine network in which the microcrystalline cellulose becomes firmer at higher temperatures. According to this principle, the three-dimensional network of the microcrystalline cellulose particles provides product stability.

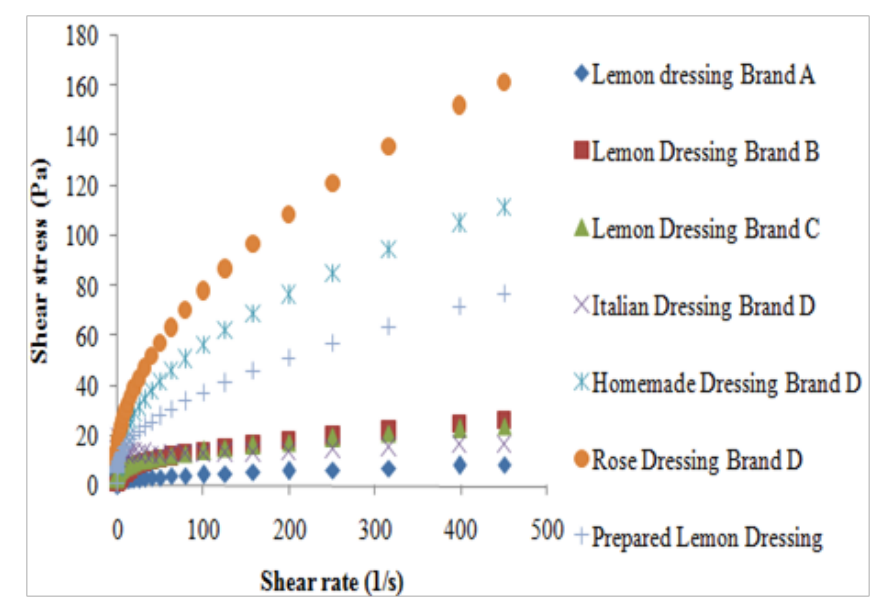

Figure I Evaluation of the variation of shear stress as a function of the shear rate for all the salad dessings studied.

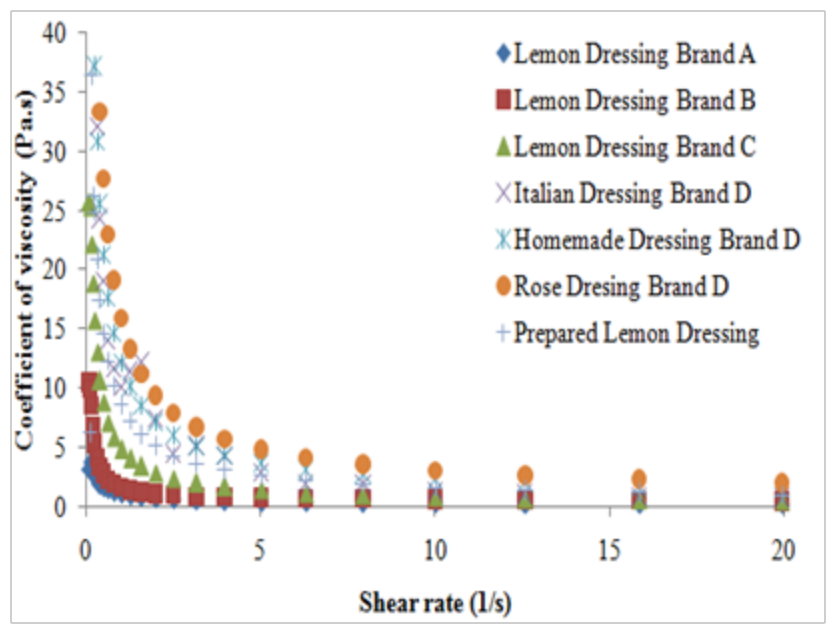

Figure 2 Evaluation of the variation of the coefficient of viscosity as a function of the shear rate for all the salad dessings studied.

The lemon flavored dressing of brand A showed lower viscosity, despite containing xanthan gum as stabilizer and modified starch in its composition. This may be due to the fact that starch may undergo viscosity loss, when exposed to acidity, and this dressing contained lemon juice; and may also be due to the fact that it presented less additives than the other dressings. Despite Italian brand D and brand B dressings presenting in its composition only xanthan gum and the brand $\mathrm{C}$ salad dressing presenting xanthan gum and also maltodextrin, they all presented similar viscosities. The same occurred with work Silva et al., ${ }^{6}$ when comparing a sample with $0.5 \% \mathrm{w} / \mathrm{v}$ xanthan gum to one with $0.5 \% \mathrm{w} / \mathrm{v}$ xanthan gum $+1.0 \% \mathrm{w} / \mathrm{v}$ maltodextrin, a similar behavior was observed; concluding that the maltodextrin has little influence over the viscosity of the samples. The Prepared Lemon dressing (PL) lemon dressing prepared with a combination of xanthan gum and maltodextrin had a higher level of viscosity than the brand $\mathrm{C}$ salad dressing. It is known that the combination of polymers to stabilize food emulsions is very common in the industry, since it is possible to reduce the amount of additives in the product and to obtain an adequate stability. The amount of polymer inserted in the manufactured product and the method of preparation is probably different from the method performed experimentally, thus providing different responses. Campos and collaborators observed that the increase in the amount of oil in the emulsion causes an increase in viscosity. ${ }^{10}$ The PL sauce was prepared with a ratio of lemon juice: oil (1:1) and was condiments were not added and other ingredients commonly used in the salad dressing industry. Therefore, it appears that the PL lemon dressing has a higher proportion of oil in relation to the salad brand $\mathrm{C}$ dressing, which also may have contributed to the behavior shown.

\section{Analysis of the stability of the emulsions}

The stability of the dressings were evaluated for longer than recommended for consumption on the product label (30 days after opening) to see if kind of changes would occur in the stability. The circularity is defined as the ratio of the value of the maximum axis to the value of the minimum axis measured for each emulsion micelle. The more this ratio approaches one, the more circular the object is. According to the results obtained by the digital image processing, all of the dressings analyzed presented $99 \%$ of circular objects throughout the experiment, indicating that there was no interference from other objects in the analysis of the micelles. The average uncertainty associated to the diameter $\left(\overline{\mathrm{a}}^{3}\right)$ was calculated for the universe of objects analyzed with a confidence interval of $99 \%$. Among the commercial samples of lemon flavored dressing (samples A, B and C) they were all classified as homogeneous and showed loss of stability by molecular diffusion due to the linear growth of the diameter of the micelles over time, as can be seen in Table 2 . This probably occurred because the xanthan gum was used in all three samples as a thickener of the aqueous phase, and according to the literature, this polymer is able to provide a creamy emulsion of the type oil in water. ${ }^{13}$ Table 2 shows the expressions of the model fit for the variation of the average diameter $\left(\overline{\mathrm{a}}^{3}\right)$ as a function of storage time for commercial lemon sauces. The homemade salad dressing was only analyzed for 70days due to micelle flocculation, which indicated destabilization of the emulsion. This sample contained xanthan gum and crystalline cellulose as thickeners. The effects of the xanthan gum are vastly known. The microcrystalline cellulose can present many uses depending on the particle size, the degree of substitution, the viscosity and the hydration characteristics. Normally it is used as a thickener and as stabilizer in products low fat products. ${ }^{14}$ Thus, these factors and the method of preparation of the emulsion may have contributed to destabilization. It is known that flocculation is a reversible process after stirring, and stirring tends to disfigure the size of the micelles studied to date, therefore it has not been possible to detect whether the phase separation of the emulsion would occur by coalescence or by molecular diffusion. In addition, the dressing was characterized as heterogeneous regarding the distribution of the micelles, probably due to the type of preparation and homogenization time. In 84days, Rose and Italian dressings did not present any visual phase separation. They were characterized as homogeneous regarding the diameter of the micelles by digital image processing and presented 
a higher concentration of micelles of the same diameter, around $3,5 \mu \mathrm{m}$ and $9,5 \mu \mathrm{m}$ respectively. This difference is probably due to the type and homogenization time. The ratio obtained by Gaussian distribution confirms the fact that the samples are homogeneous and have not presented diameter increase during the study period, since the ratio of the widths of the peaks as well as the first day of the Gaussian analysis in relation to the last day were less than 1.0. The PL Lemon dressing was characterized as heterogeneous by the Gaussian analysis, and it was not possible to determine the type of destabilization, coalescence or molecular diffusion, since it was not possible to observe whether the growth tendency over time would be linear or exponential (Figure $3)$. Therefore, it can be noticed that the type, the amount and the method of preparation of the emulsions influence the oil droplet size and hence the stability of the product. Xanthan gum is one of the most commonly used polymers in the food industry and highly thickening. The combinations with other additives that have the same purpose provide lower cost and increased potential.

Table 2 Correlation coefficient of mechanisms of stability loss of the studied emulsions during 84 days $\left(\overline{\mathrm{a}}^{3}=\right.$ droplet diameter $\left(\mu \mathrm{m}^{3}\right)$ and $\mathrm{t}=$ time $($ days $\left.)\right)$

\begin{tabular}{lll}
\hline Salad dressings & Fitted equation & $\mathbf{R}^{2}$ \\
\hline Brand A & $\overline{\mathrm{a}}^{3}=21,658 \mathrm{t}+124,91$ & 0,94 \\
Brand B & $\overline{\mathrm{a}}^{3}=82,404 \mathrm{t}+438,63$ & 0,96 \\
Brand C & $\overline{\mathrm{a}}^{3}=11,183 \mathrm{t}+499,74$ & 0,94 \\
Prepared Lemon & $\overline{\mathrm{a}}^{3}=76,515 \mathrm{t}+450,62$ or $\overline{\mathrm{a}}^{3}=934,82 \mathrm{e}^{0,0218} \mathrm{t}$ & 0,42 or 0,38 \\
Dressing & & \\
Italian Brand D & $\overline{\mathrm{a}}^{3}=-3,6 \mathrm{t}+1026$ or $\overline{\mathrm{a}}^{-3}=1025,6 \mathrm{e}^{-0,004} \mathrm{t}$ & 0,72 or 0,69 \\
Caseiro Brand D & $\overline{\mathrm{a}}^{3}=1,0756 \mathrm{t}+167,98$ or $\overline{\mathrm{a}}^{3}=175,62 \mathrm{e}^{0,0047} \mathrm{t}$ & 0,94 or 0,93 \\
Rose Brand D & $\overline{\mathrm{a}}^{3}=-0,1834 \mathrm{t}+53,28$ or $\overline{\mathrm{a}}^{3}=54,025 \mathrm{e}^{-0,004} \mathrm{t}$ & 0,47 or 0,49
\end{tabular}

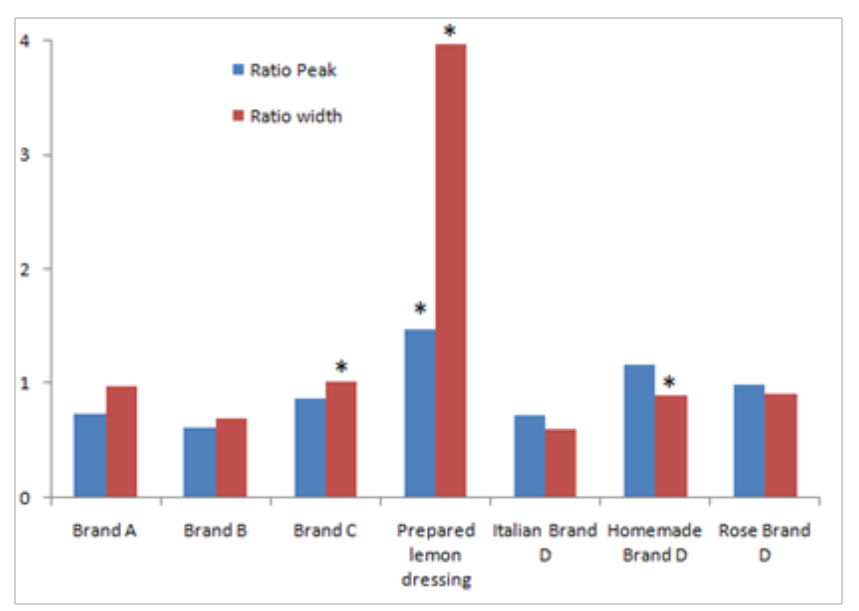

$*$ Width $=$ heterogenous emulsion and peak $=$ dislocated for large values of droplets.

Figure 3 Distribution of droplet size in the studied emulsions. Ratio of widths and peaks of the guassian graphs of the last day to day 0 of the experiment.

\section{Conclusion}

In this work observed that the dressing's salads containing modified starch as an additive, showed higher viscosity compared to those that contained xanthan gum associated with maltodextrin or propylene glycol alginate. However, when it added to the sauce containing lemon juice, this behavior was reversed, certainly due to the higher $\mathrm{pH}$ of the product. Therefore, it is necessary to adequately determine the quantities of the ingredients in the product to establish the best composition of polymers to be used in product stability. The results about of stability study by digital image processing showed that three commercial lemon-flavored dressings suffered destabilization by molecular diffusion due to the linear increase the diameter of micelles over time. It was not possible to identify the type of destabilization for the Italian and Rose dressings throughout the study period. As for the lemon sauce prepared, although it was identified that there was destabilization by the significant increase in diameter, it was not possible to identify the type of mechanism so far. Although, homemade dressing type was characterized as being heterogeneous and clearly showed flocculation. During the 84 days of storage, the dressings maintained their visual characteristics, except for the brand B dressing, which clearly showed phase separation since the beginning, but became homogeneous with agitation. It is necessary to evaluate the percentage of each type of biopolymers in the product in to have better view of its effect on the stability of salad dressings. With this study it was possible to visualize processes of destabilization and contribute to characterization commercial products, allowing to improve future emulsified food formulations. Furthermore, it was shown that the digital image processing could be an additional tool to contribute to such characterization.

\section{Acknowledgements}

None.

\section{Conflict of interest}

The author declares no conflict of interest.

\section{References}

1. Pedrini H, Schwartz WR. Análise de Imagens Digitais: Principios algoritimos e aplicações. Thomson Pioneira, Portugese; 2007. 528 p.

2. Albuquerque MP. Processamento de imagem: métodos e análises. Centro Brasileiro de Pesquisas Físicas - CBPF/MCT. Coordenação de Atividades Técnicas - CAT, Rio de Janeiro, Portugese; 2013. p. 1-15.

3. Fonesca VC. Elaboração de molho para salada com soro de queijo minas frescal estabilizado por combinação ternária de alginato de propileno glicol, goma xantana e carboximetilcelulose. Universidade Federal Do Paraná; 2008. p. 1-132.

4. Ferreira EV, Brandao PR, Klein B, et al. Reologia de suspensões minerais: uma revisão. Rem: Revista Escola de Minas. 2005;58(1):83-87.

5. McClements DJ. Food emulsions: principles, practice and techniques. USA: CRC press; 1999. p. 339-362.

6. Silva KA, Rocha-leao MH, Coelho MA. Evaluation of aging mechanisms of olive oil-lemon juice emulsion through digital image analysis. Journal of Food Engineering. 2010;97(3):335-340.

7. Freire MG, Dias AM, Coelho MA, et al. Aging mechanisms of perfluorocarbon emulsion using image analysis. $J$ Colloid Interface Sci. 2005;286(1):224-232. 
8. Fox WR, Mcdonald AT, Pritchard PJ. Introdução a Mecânica dos Fluidos. 6th ed. Rio de Janeiro, Portugese: LTC; 2006.

9. Braun DB, Rosen MR. Rheology Modifiers Handbook. Practical Use and Application. New York, USA: William Andrew publishers; 2000. 513 p.

10. Campo DCP, Antoniassi R, Deliza R, et al. Soy - based low fat emulsion: stability, rheology, nutritional value and consumer acceptance. Food Science and Technology (Campinas). 2000;29(4):919-926.

11. Ordónez JA, Rodriguez MIC, Álvarez LF, et al. Tecnologia de Alimentos In: Porto Alegre editor. Componentes dos Alimentos e Processos. Artmed; 2005. 294 p.
12. Fennema OR, Damodaran S, Parkin KL. Fennema's Food Chemistry. 4th ed. UK: CRC Press/Taylor \& Francis; 2007. 1144 p.

13. Vélez G, Fernández MA, Muñoz J, et al. Role of hydrocolloids in the creaming of oil in water emulsions. J Agric Food Chem. 2003;51(1):265269.

14. Food Ingredients Brasil $N^{\circ} 27$ Celulose Microcristalina. A celulose Microcristalina na Indústria Alimentícia; 2013. p. 1-5. 